\title{
Commercialization of active packaging: Expectation vs reality
}

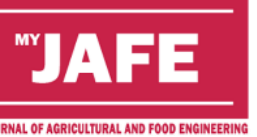

Ruzanna Ahmad Shapi'i a,b

aDepartment of Process and Food Engineering, Faculty of Engineering, Universiti Putra Malaysia, 43400 UPM Serdang, Selangor, Malaysia ${ }^{b}$ Materials Processing and Technology Laboratory, Institute of Advanced Technology, Universiti Putra Malaysia, 43400 Serdang, Selangor, Malaysia.

\section{ARTICLE HISTORY}

Received: 18 August 2020

Received in revised form: 25 August 2020

Accepted: 10 September 2020

Available Online: 16 September 2020

Traditional food packaging materials do not interact with food and only serve to isolate food from the environment (Dairi, Ferfera-Harrar, Ramos, \& Garrigós, 2019). Therefore, it is not effective in ensuring the food quality and food safety meet for required regulation in food processing industry. Active packaging which made from natural material such as biopolymers (starch, chitosan, seaweed, cellulose) offers advanced features that make it possible to optimize the conditions inside the packaging of a food product, thus extending the food shelf-life. For examples, starch-based films that incorporated with chitosan nanoparticles able to inhibit the microbial growth in food package, thus extend the shelf life of food product (Shapi'i, Othman, Nordin, Basha, \& Naim, 2019). Further exploration of the commercialization of active packaging material is needed in order to produce an effective packaging material for food applications. There are several challenges that should be considered before starting the commercialization process of active packaging made from biopolymer materials in industrial scale. Figure 1 shows the processes of product commercialization which include experimentation, process scale up, technology transfer, and process improvement.

Based on Figure 1, the process of product commercialization should be started with experimentation, which is also known as research and development (R\&D) process. Development of biopolymer materials requires a lab-based approach where product formulation and characterization are initially demonstrated and analyzed in a laboratory. The possible risks shall be evaluated and used to predict the efficiency of new technology application in large-scale industrial operations. The processing of new biopolymer material usually does not always extend into the manufacturing capacity smoothly due to common scenarios that occur in the packaging industry. Larger batches, different conditions of the process and various material types (tapioca starch, corn starch, wheat starch, chitosan) can cause unexpected performance issues and inconsistent quality of product. However, laboratory and pilot plant scale can be a great indicator of scale-up processing in large manufacturing scale. Furthermore, some measures could be taken to optimize the probability of successful laboratory and pilot scale production. When the optimization process is carried out correctly, smallscale production in pilot scale can give an accurate and precise forecast of the produced films in the large-scale production.

As reported by Matser, Mastwijk, \& Houska (2010), it is very important to consider the availability of following equipment and facilities before perform the scale-up process:

Laboratory-scale equipment should be available for trials with model systems and to build a scientific knowledge that is able to describe the molecular interactions of all raw material during and after processing, significant processing parameter, and interaction of active packaging material with real food.

ii) Pilot-scale equipment should be accessible to perform small trials of processing whereby the type of equipment should be similar with the industrial scale but smaller than industrial. The product of pilot-scale study should provide more information on the effect of processing conditions on shelf life and quality, and establish any implications, seen and unforeseen. Typically, pilot-scale systems are used for feasibility, optimization, prediction, and demonstration activities.

iii) Industrial scale equipment, including pre-processing and post-processing facilities are essential for proper implementation of the process in the industry, thus large amount of product can be produced in short time. It is compulsory that equipment can control the full process and allow the trouble shooting of process including do a proper comparison with products from other systems or different parameters.

For the successful commercialization of new material products, it is important for reliable equipment that have been

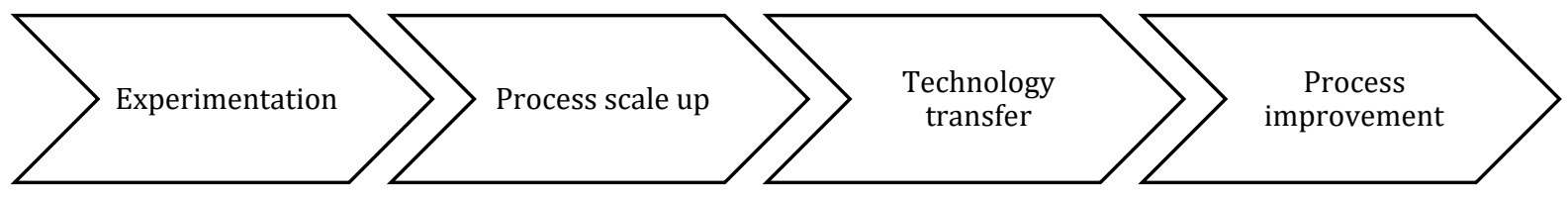

Figure 1. Process of product commercialization 
used in laboratory and pilot-scales is similar with the existing equipment in industry. Researcher and industrial stakeholders play an important role to collaborate and implement the knowledge transfer, thus both parties in research institute and industry can complement to each other. However, most of the packaging industries are still using the old-fashioned processing equipment which is also used for conventional non-degradable packaging material (PP, PVC, PVA). This real scenario in packaging industry will make the commercialization process for biodegradable material become very difficult. Note that biopolymer film processing is different with the conventional film due to different raw material properties, processing parameter and additional processing steps. Installation of new technology for biopolymer processing required large cost including new machine, new expertise, operator training, and factory expansion. These issues will lead to a higher price of biodegradable film as compared to the conventional film. Although the starting cost for commercialization of biopolymer film is high, it is expected that this initiative will provide longterm profit with the sustainable source of raw materials. Government or private agency should play an important role to provide grant or incentive for packaging industry that takes an initiative to start producing the biopolymer-based materials.

The difference in each batch of raw materials used during processing is also one of the common challenges in commercialization of biopolymer packaging. Naturally, biopolymers may come in different physical and chemical compositions due to the difference in species, origin, climate, geography, collection, and storage time materials (Sam, Nuradibah, Chin, \& Hani, 2015). Inconsistent quality of raw materials will lead to the inconsistency of final products quality in terms of physical, mechanical, and chemical properties. In order to overcome this challenge, it is very important for the industrial organization to figure out the best system in the factory. It is very important to control the quality, type and origin of raw materials. Most of the manufacturing industry will accept raw materials from the same supplier for every batch of production. Each batch of the received raw materials should be tested and characterized before used in the production line. The strict quality control of the raw materials used before and during processing will minimize unexpected problems during processing, thus prevent the stakeholders' losses and promise the consistency of product quality.

Although there are a lot of obstacles that exist during the product commercialization process, the effort to produce active packaging film made from biopolymer is worth it to many parties in the long-term. It is very crucial to start the commercialization of biopolymer-based materials that is more sustainable, safe, and environmentally friendly.

\section{Acknowledgment}

Author gratefully acknowledge Universiti Putra Malaysia for the access to scientific journals. Author also thank the Associate Professor Dr Siti Hajar Othman, Associate Professor Dr Mohd Nazli Naim and Dr Intan Syafinaz from Faculty of Engineering, Universiti Putra Malaysia, Malaysia for constructive advice and suggestion.

\section{Author contributions}

The author confirms sole responsibility for the following: case study, literature review, idea brainstorm, analysis and interpretation of findigs, and manuscript preparation.

\section{Conflict of interests}

The author declares no conflict of interest.

\section{References}

Dairi, N., Ferfera-Harrar, H., Ramos, M., \& Garrigós, M. C. (2019). Cellulose acetate/AgNPs-organoclay and/or thymol nanobiocomposite films with combined antimicrobial/antioxidant properties for active food packaging use. International Journal of Biological Macromolecules, 121, 508-523. https://doi.org/10.1016/j.ijbiomac.2018.10.042

Matser, A., Mastwijk, H., \& Houska, M. (2010). From laboratoryscale to pilot-scale. Retrieved May 29, 2020, from https://www.newfoodmagazine.com/article/3052/fromlaboratory-scale-to-pilot-scale/ 7/9

Sam, S. T., Nuradibah, M. A., Chin, K. M., \& Hani, N. (2015). Natural polymers: Industry techniques and applications. Natural Polymers: Industry Techniques and Applications, 1-370. https://doi.org/10.1007/978-3-319-26414-1

Shapi'i, R. A., Othman, S. H., Nordin, N., Basha, R. K., \& Naim, M. N. (2019). Antimicrobial Properties of Starch Films Incorporated with Chitosan Nanoparticles: In Vitro and In Vivo Evaluation. Carbohydrate Polymers, (August), 115602.

https://doi.org/10.1016/J.CARBPOL.2019.115602 